\title{
Detection and molecular characterization of porcine circovirus type 2 from piglets with Porcine Circovirus Associated Diseases in Colombia
}

Maria Antonia Rincón Monroy ${ }^{1,2^{*}}$, Gloria Consuelo Ramirez-Nieto², Victor Julio Vera², Jairo Jaime Correa ${ }^{2}$ and Jose Dario Mogollón-Galvis ${ }^{2}$

\begin{abstract}
Background: The porcine circovirus-associated disease (PCVAD) has been known since 1991 in Canada, but the first outbreak of PCVAD in Colombia was reported in 2007. In order to understand the molecular epidemiology of the disease and to establish the origin of the virus in the country, the study presented here intended to evaluate the presence of PCV2-associated systemic infection in piglets from different geographical regions over a period of 9-years (2002 -2010). The analysis included samples collected before, during and after outbreaks of PCVAD in pigs from Colombia. The PCV2 ORF2 from the positive samples was sequenced and used to determine the genotypes of the strains and to study the dynamic of these genotypes throughout the time.

Results: PCV2 DNA was detected in cases related to PCV2-associated systemic infection as well as in healthy pigs with a presumable persistent infection. The analysis of the ORF2 nucleotide full length sequence of twenty-three strains allowed to divide them into two groups: PCV2a and PCV2b. At the amino acid level the main variations in the sequence of the capsid protein were found in regions located within the immunoreactive areas.

Conclusions: The results of this study demonstrated for the first time, that the two subgroups: PCV2a and PCV2b have been circulating in swine from Colombia. In addition, the study showed that genotype PCV2b is present in Colombian pigs suffering from both clinical and presumable persistent infection and that the PCV2b genotype was present in the Colombian pig population even before recognition of the disease in the country and it became predominant through time.
\end{abstract}

Keywords: Porcine circovirus type 2 (PCV2), Porcine circovirus-associated disease (PCVAD), Genetic characterization

\section{Background}

Porcine circovirus type 2 (PCV2), a member of the Circoviridae family, is a small non-enveloped virus, containing a single-stranded circular deoxyribonucleic acid (DNA) genome [1], it is distributed worldwide and is considered to be an important emerging pathogen associated with several different syndromes and diseases in pigs, collectively grouped as porcine circovirus diseases (PCVD) [2]. PCV2 is the major infectious agent of PCVAD in pigs,

\footnotetext{
* Correspondence: marinconm@unal.edu.co

'Colombian Agriculture Institute - ICA, National Laboratory of Veterinary Diagnostic, Bogotá D.C, Colombia

${ }^{2}$ National University of Colombia, School of Veterinary Medicine, Carrera 30 No. 45-03, Edificio 561B, Bogotá D.C, Colombia
}

a multifactorial disease, considered one of the most economically important swine diseases worldwide [3]. PCV2associated systemic infection is clinically characterized by wasting, dyspnea, and lymphadenopathy and might be associated with diarrhea, pallor, and jaundice [4]. The most relevant histological lesions in this condition occur in lymphoid organs and consist of extensive lymphocytic depletion, macrophage infiltration, a few multinucleated giant cells, and botryoid basophilic cytoplasmic inclusion bodies [5].

PCV2 DNA genome is about $1767-1768$ nucleotides long [6] and encodes for three open reading frames (ORFs) [7]. The ORF1 encodes the replication-related 
proteins: Rep (helicase) and Rep' (nickase) that is the result of Rep-transcript alternative splicing process $[8,9]$. The ORF2 encodes the capsid protein, the only structural viral protein that is also the most variable nucleotide sequence of the viral genome $[10,11]$. Finally, the ORF3 embedded within ORF1, encodes a protein that is not essential for viral replication but is fundamental to the development of the viral pathogenesis $[12,13]$.

PCV2 is classified into two main genotypes, PCV2a and PCV2b which were further subdivided into different clusters, $1 \mathrm{~A}-1 \mathrm{C}$ and $2 \mathrm{~A}-2 \mathrm{E}$ for PCV2b and PCV2a, respectively [11]. A third genotype, PCV2c, has only been found in Denmark [14]. A new type of PCV referred to as PCV1/2a was reported in Canada in 2009, it was found to be a chimeric virus containing ORF1 of PCV1 and ORF2 of PCV2a [15]. Recently, two additional genotypes PCV2d and PCV2e, were described following sequence analysis of PCV2 isolates from China [16]. However, a subsequent analysis of data sequences failed to support the new genotypes reported [17].

In South America, PCV2 has been circulating in Brazil since 1988 [18], but it was also detected in Argentina $[19,20]$, and Chile [21]. PCV2-associated systemic infection was first reported in 2007 [22] in Colombia from pig farms located in different regions. In spite of that, genetic information about PCV2 strains in pig herds from the country had been unavailable until now. The main purpose of this work was to establish molecular detection and to achieve genetic and phylogenetic comparisons of full-length sequences of the ORF2 from PCV2 strains recovered from clinically healthy and PCV2-associated systemic infection affected pigs from different production systems in Colombia. Another purpose was to study the viral genotypes dynamics through time to trace temporal changes, in order to understand the molecular epidemiology of PCV2 in Colombia.

\section{Results \\ PCV2 DNA detection}

The results of the amplification of the PCV2 in serum samples tested by conventional PCR are illustrated in Figure 1. A total of 21 out of 110 whole serum samples (19.1\%) collected during 2002 - 2005 were positive to PCV2. Those samples were from 13 farms located in Cundinamarca (6), Risaralda (4) and Valle (3). The two oldest positive samples detected in farms from Valle and Risaralda were from 2002 (Table 1). Additionally, PCV2 DNA was identified in 11 archived necropsy samples collected during PCVAD outbreaks that occurred in Colombia during 2006-2007. On the other hand, from the samples collected over the period of 2009 - 2010, PCV2 DNA was identified in 34 serum samples (25.2\%) from 14 farms (51.8\%) and in 40 tissue samples (80\%) from 50 pigs that showed clinical signs compatible with

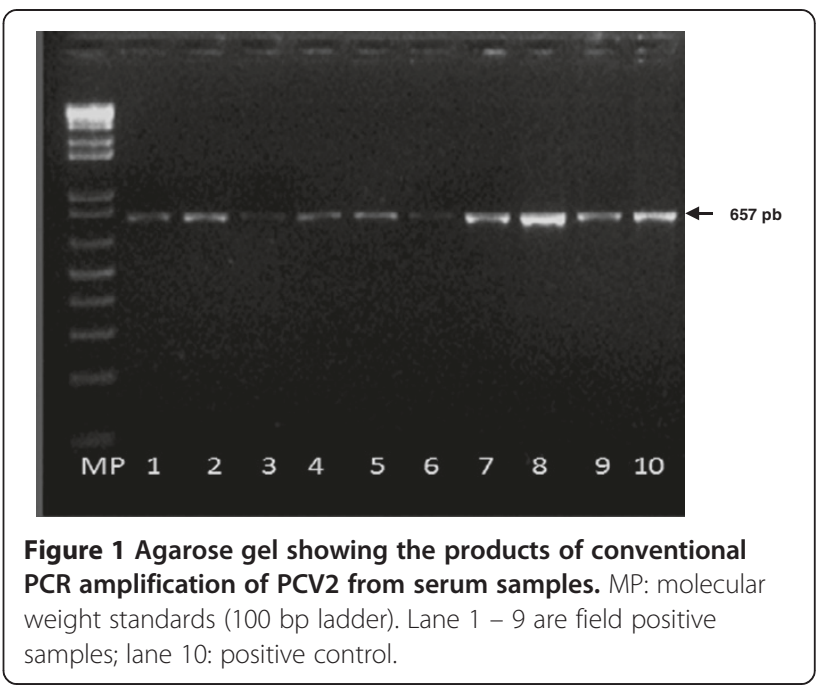

PCV2-associated systemic infection (Table 2). It is important to mention that PCV2 antigen was demonstrated previously by IHC in the lymph nodes of these 40 PCR positive samples. Detection was also associated with histological changes suggestive of PCV2-associated systemic infection (granulomatous inflammation and lymphoid depletion) [23].

\section{PCV2 PCR specificity and sensitivity}

There was no amplification with the designed primers for PCV2 ORF2 for any of the four bacterial or the five viral nucleic acids from swine pathogens used to test the specificity of the PCR under the conditions used in this study. The conventional PCR test detected PCV-2 DNA up to a dilution of $10^{-3}$, corresponding to $2.2 \times 10^{3}$ TCID50/ml.

\section{Genetic characterization}

The complete genome of 23 Colombian ORF2 PCV2 sequences showed a length of $702 \mathrm{bp}$ and revealed a

Table 1 PCV2 DNA detection in serum samples and tissue samples collected during 2002-2007

\begin{tabular}{|c|c|c|c|}
\hline \multirow[t]{3}{*}{ Year } & \multicolumn{2}{|c|}{ Conventional PCR } & \multirow{3}{*}{$\frac{\text { Positive tissue }}{\text { samples** }}$} \\
\hline & Positive farms* & Positive serum & \\
\hline & & samples** & \\
\hline 2002 & $2 / 2$ & $2 / 10$ & \\
\hline 2003 & $3 / 6$ & $4 / 30$ & \\
\hline 2004 & $4 / 9$ & $6 / 45$ & \\
\hline 2005 & $4 / 5$ & $9 / 25$ & \\
\hline 2006 & & & $6 / 6$ \\
\hline \multirow[t]{2}{*}{2007} & & & $5 / 5$ \\
\hline & $13 / 22(59.1 \%)$ & 21/110 (19.1\%) & $11 / 11(100 \%)$ \\
\hline
\end{tabular}

*Positive farms/total examined.

**Positive samples/total examined. 


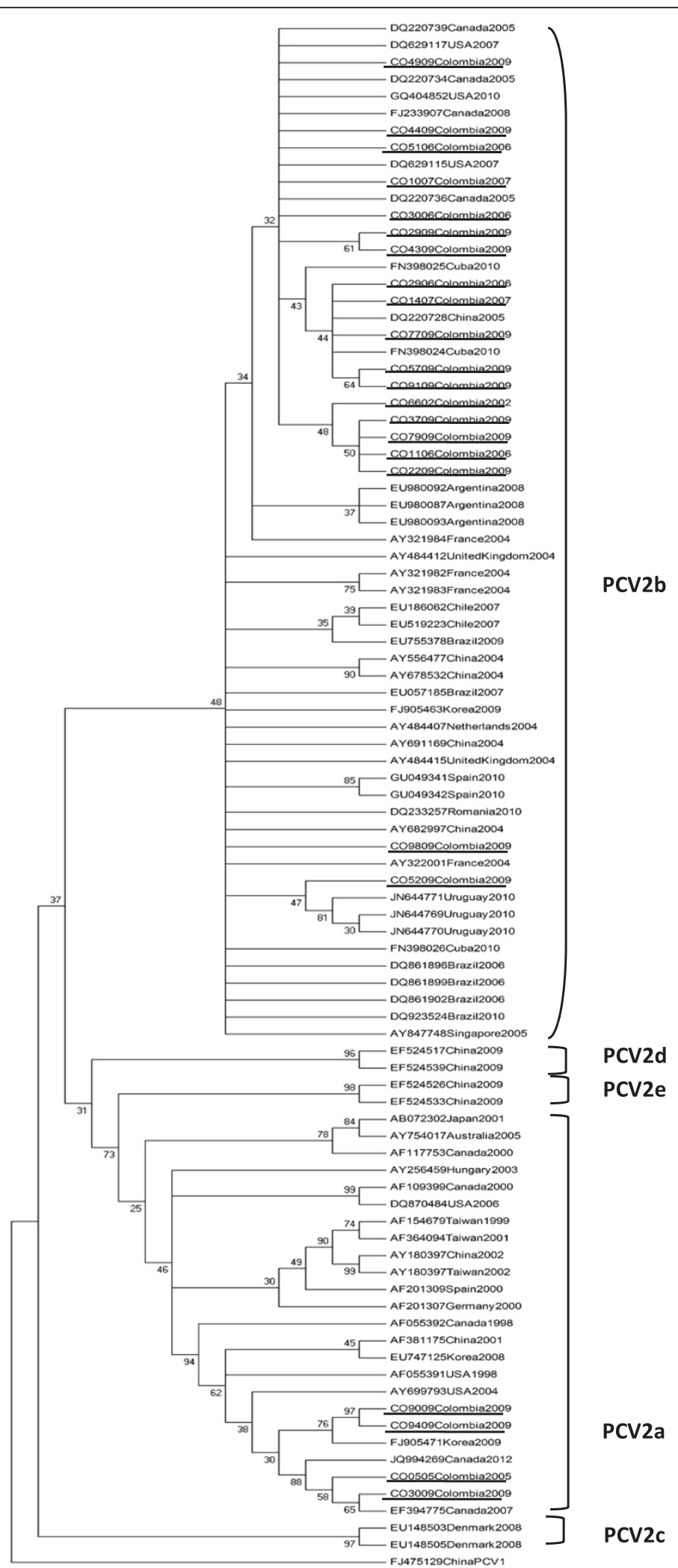

Figure 2 Phylogenetic tree constructed by the neighbor-joining method based on the complete 702-nt sequence of the PCV2 ORF2. PCV2 Colombian strains evaluated in this study are shown underlined. Sixty eight strains whose entire or partial sequences have been reported were included for comparison. PCV1 isolate FJ475129 was included as outgroup. 
Table 2 PCV2 DNA detection in serum samples and cases collected during 2009-2010

\begin{tabular}{|c|c|c|c|c|}
\hline \multirow{4}{*}{$\begin{array}{l}\text { Geopraphic } \\
\text { origin }\end{array}$} & \multicolumn{4}{|c|}{ Conventional PCR } \\
\hline & \multicolumn{2}{|c|}{ Serum samples } & \multicolumn{2}{|c|}{ Tissue samples } \\
\hline & Positive* & Positive ${ }^{* *}$ & Positive* & Positive** \\
\hline & Farms & serum & Farms & tissue \\
\hline Antioquia & $7 / 10$ & $20 / 50$ & $6 / 6$ & $15 / 15$ \\
\hline Cundinamarca & $2 / 7$ & $4 / 35$ & $6 / 6$ & $12 / 21$ \\
\hline Risaralda & $3 / 5$ & $3 / 25$ & $1 / 2$ & $3 / 4$ \\
\hline \multirow[t]{2}{*}{ Valle } & $2 / 5$ & $7 / 25$ & $4 / 4$ & $10 / 10$ \\
\hline & $14 / 27$ & $34 / 135$ & $17 / 18$ & $40 / 50$ \\
\hline
\end{tabular}

*Positive farms/total examined.

**Positive samples/total examined.

nucleotide identity of $91.4 \%-100 \%$ among them. At the nucleotide level, the PCV2a and PCV2b sequences shared between them an identity of $98 \%-100 \%$ and $98.8-100 \%$ respectively. The two genotypes of the PCV2 were found both in the strains isolated from PCV2associated systemic infection affected animals and in those from healthy pigs belonging to the main pigproducing provinces of Colombia. The sequence analysis showed that PCV2b is the predominant genotype in Colombia (Figure 2). Interestingly, in two farms (farms 2 and 7), both genotypes, PCV2a and PCV2b, were detected before the first outbreak and they were also discerned during and after outbreaks of PCVAD in Colombia (Table 3).

The PCV2b Group included 19 strains that contained the signature motif CCCCGC encoding proline $(\mathrm{P})$ and arginine (R) at nucleotides $262-267$ and amino acids 88-89. Fifteen nucleotide substitutions that originated five amino acid substitutions: I57V, R63K, A190T, L226F and D228A were observed in the ORF2 from the PCV2b Colombian strains. On the other hand, the PCV2a Group consisted of four strains with the nucleotide sequence AAAATC encoding lysine (K) and isoleucine (I). Sixteen nucleotide substitutions were observed in the ORF2 from the PCV2a Colombian isolates, which led to twelve amino acid substitutions: T47A, R59A, T63R, K75N, L76I, T134N, L136Q, L183I, L187I, K206I and $\mathrm{N} 232 \mathrm{~K}$. In this study the main positions of amino acid replacements among Colombian ORF2 PCV2 sequences were located at amino acid positions 57-89, 121-134 and 190-210 (Figure 3).

\section{Phylogenetic analyses}

The phylogenetic analysis of the 23 ORF2 PCV2 sequences from this study along with 68 sequences published in the GenBank database that are representative of all PCV2 genotypes is shown in Figure 2. The phylogenetic tree reproduces all the PCV2 clusters previously described [11]. The 23 strains were divided into the two genotypes defined earlier, PCV2b $(n=19)$ and PCV2a $(\mathrm{n}=4)$.

According to the nomenclature previously established [24] and supported by high confidence values, the ORF2 sequences from four Colombian PCV2a, were grouped with those described as the PCV2 emergent variants associated with severe porcine circovirosis reported in Canada (1998, 2007, 2012), USA (1998, 2004), China (2001), and Korea $(2008,2009)$ in a defined cluster within the genotype PCV2a (Figure 2). The remaining PCV2 sequence was clustered within the genotype PCV2b closely related to published sequences from Canada (2007, 2012), USA (2007 - 2010), as well as European, Asian, Caribbean and South American strains.

Sequence analysis and comparison of Colombian PCV2b sequences with strains reported from South America showed a very high level of homology. Identity of $98.1 \%-99.8 \%$ at the nucleotide level and $94.4 \%$ $97.8 \%$ at the amino acid level was found when compared with six of the Brazilian strains included in this study (accession numbers DQ861896, DQ861899, DQ861902, EU057185, DQ923524 and EU755378). The comparison with Argentinean strains (EU980087, EU980092 and EU980093) revealed an identity ranging from 99\% to $99.8 \%$ and $98.7 \%$ to $100 \%$ at the nucleotide and amino acid level, respectively. At the same time, Colombian PCV2b strains showed a high nucleotide (98.4\%-99.7\%) and amino acid (94.4\%-97.8\%) identity with three of the Uruguayan strains included in this study (JN644769, JN644770 and JN644771). By contrast, the comparison with two Chilean strains revealed identity ranging from $92 \%$ to $95.8 \%$ at the nucleotide and $90.5 \%$ to $95.2 \%$ at the amino acid level.

\section{Discussion}

PVC2 was detected in Colombian pigs associated with a wide variety of clinical conditions as described previously $[22,23]$. In this study, the presence of PCV2 was demonstrated by PCR in $22.4 \%$ of the serum and $83.6 \%$ of the tissue samples examined. The identification of PCV2 not only in cases associated with PMWS but also in healthy pigs, suggests that various risk factors may contribute to the exacerbation of PCV2 infection and the development of associated lesions. An epidemiological survey of PCVAD conducted between November 2008 and December 2009 in Colombia identified some factors associated with high mortality rates in the three major swine rearing areas in the country [22,23]. Herds that did not have good management practice, presence of poliserositis in weaned pig and low feed intake resulted in a major risk of increased mortality. In that study it was found that vaccination against PCV2, authorized since 2008, represented a high effective 
Table 3 Origin of 23 Colombian PCV2 ORF2 sequences examined in this study

\begin{tabular}{|c|c|c|c|c|c|c|}
\hline Year of the colection & PCV2 strain ID/original name & Geographic origin & Farm No. & $\begin{array}{l}\text { Designation clinical } \\
\text { condition }\end{array}$ & Sample origin & Genotype \\
\hline 2002 & $\mathrm{CO} 6602$ & Valle & 7 & Non Wasting & serum & $P C V-2 b$ \\
\hline 2005 & CO0505 & Cundinamarca & 2 & non wasting & serum & PCV-2a \\
\hline 2006 & C01106 & Cundinamarca & 2 & Wasting & lymphoid node & $P C V-2 b$ \\
\hline 2006 & CO2906 & Valle & 7 & Wasting & lymphoid node & $P C V-2 b$ \\
\hline 2006 & CO3006 & Valle & 18 & Wasting & lymphoid node & $P C V-2 b$ \\
\hline 2006 & CO5106 & Valle & 10 & Wasting & lymphoid node & $P C V-2 b$ \\
\hline 2007 & CO1007 & Cundinamarca & 6 & Wasting & lymphoid node & $P C V-2 b$ \\
\hline 2007 & CO1407 & Antioquia & 13 & Wasting & lymphoid node & $P C V-2 b$ \\
\hline 2009 & C02239 & Antioquia & 22 & Wasting & lymphoid node & $P C V-2 b$ \\
\hline 2009 & CO2909 & Valle & 8 & non wasting & serum & $P C V-2 b$ \\
\hline 2009 & CO3009 & Valle & 21 & non wasting & serum & PCV-2a \\
\hline 2009 & CO3739 & Valle & 37 & Wasting & lymphoid node & $P C V-2 b$ \\
\hline 2009 & CO4309 & Valle & 8 & Wasting & lymphoid node & $P C V-2 b$ \\
\hline 2009 & CO4409 & Antioquia & 12 & non wasting & serum & $P C V-2 b$ \\
\hline 2009 & CO4909 & Cundinamarca & 1 & Wasting & lymphoid node & $P C V-2 b$ \\
\hline 2009 & CO5209 & Antioquia & 29 & Wasting & lymphoid node & $P C V-2 b$ \\
\hline 2009 & CO5709 & Antioquia & 26 & Wasting & lymphoid node & $P C V-2 b$ \\
\hline 2009 & CO7709 & Antioquia & 5 & Wasting & lymphoid node & $P C V-2 b$ \\
\hline 2009 & CO7909 & Antioquia & 28 & Wasting & lymphoid node & $P C V-2 b$ \\
\hline 2009 & CO9009 & Valle & 18 & Wasting & lymphoid node & PCV-2a \\
\hline 2009 & CO9109 & Antioquia & 29 & non wasting & serum & $P C V-2 b$ \\
\hline 2009 & CO9409 & Valle & 18 & Wasting & lymphoid node & PCV-2a \\
\hline 2009 & C09809 & Risaralda & 20 & non wasting & serum & $P C V-2 b$ \\
\hline
\end{tabular}

intervention practice on controlling PCAVD outbreak even though PCV2 infection itself wasn't considered a risk factor for PCVAD development. It remains unclear which factors contributed to maintain a subclinical PCV2 infection in Colombian swine herds and thus it needs to be further investigated.

Unfortunately, samples collected before 2002 were not available at the time of the study, but it is reasonable to assume that PCV2 was already present in the Colombian pig population prior to this time frame. The earliest confirmed detection of PCV2 worldwide was in 1962 in Germany [25], before that, the virus was probably causing subclinical infections or remained unknown for many decades before the description of PCVAD as a disease complex. An alternative to gain access to the knowledge of the PCV2 infection is the use of archived material, it is how in the UK investigations in archived formalin-fixed material established PCV2 detection using TaqMan1-PCR and immunohistochemistry in material originated from the 1970s [26]. The earliest PCV2 infection in Swiss archived material was found in 1986 by using immunohistochemistry, resulting in the recognition of the earliest histological lesions typical for PCV2-associated systemic infection [27]. Similarly, a study from Spain revealed the presence of PCV2 in archived material from 1985 onwards, and the occurrence of typical PCV2-associated systemic infection lesions as early as 1986 [28]. A retrospective study of PCV2 infection in Japan reported seven cases in 1989 [29]. Also, the earliest PCV2 infection in Thailand was reported in 1993 by using Nested PCR from formalin fixed tissues of PCV2-associated systemic infection affected pigs [30].

When considering Colombia, the data presented here showed an increase in the incidence of PCV2b infection between 2006-2007, in that period PCVAD was epizootic and caused problems in numerous farms in several provinces [22]. During that time, PCV2 positive samples by immunohistochemistry were collected from pigs showing characteristic lesions of PCV2-associated systemic infection and some of them were later studied by PCR. As mentioned earlier, 50 cases were collected from pigs with wasting problems during a time period between 2009 -2010. Forty of these samples were PCR positive and PCV2 DNA was identified in the $25.2 \%$ of the serum 


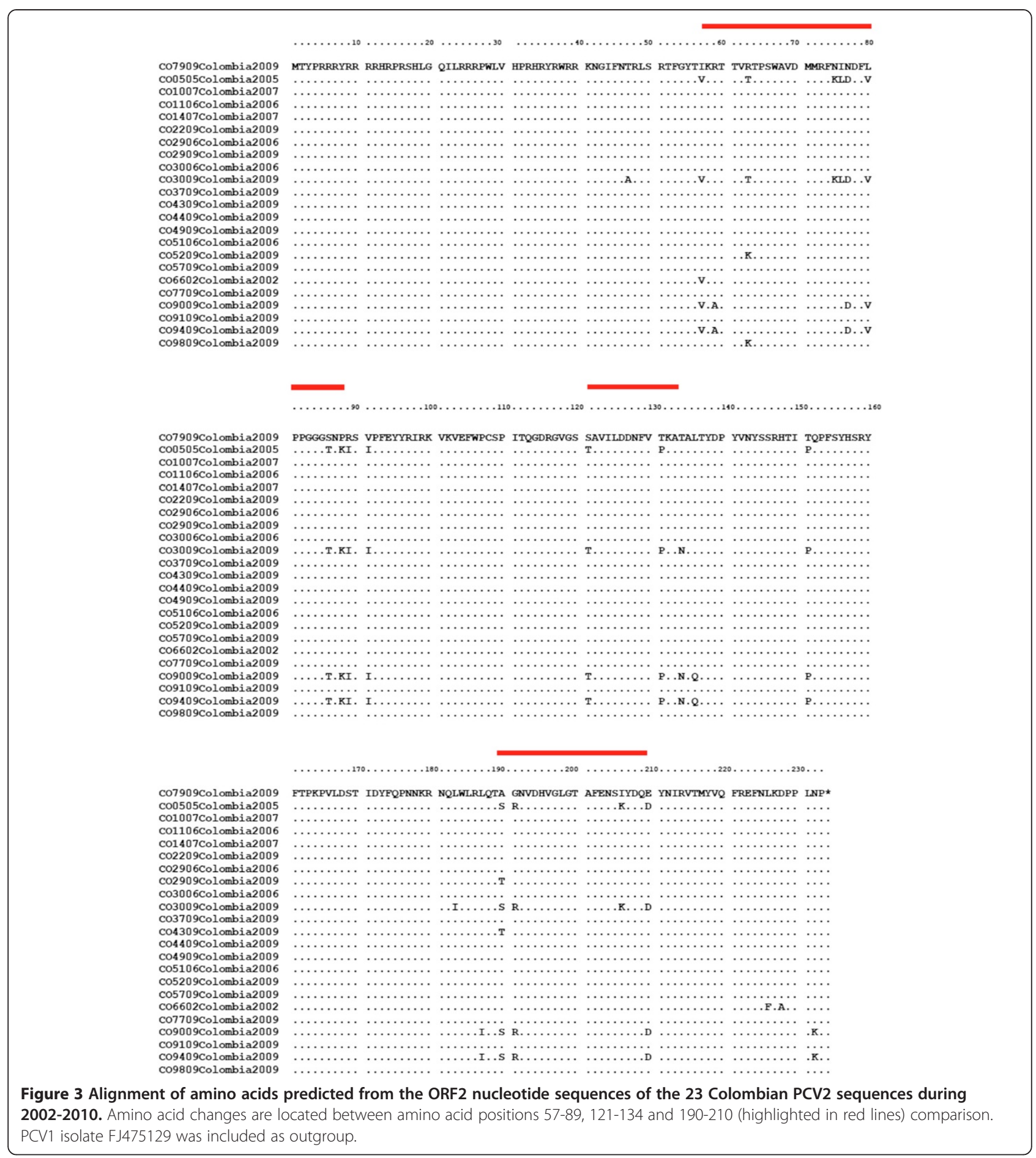

samples collected at that time from healthy pigs. It is well known that detection of PCV2 alone, without the three criteria for diagnostic of PCVAD, does not indicate PCVAD but merely PCV2 infection [3]. However, there was no evidence that could relate the PCV2 strain groups and pathogenic PCV2 isolates from PCV2associated systemic infection cases and besides that it cannot be concluded that PCV2 isolates from healthy pigs are non-pathogenic.

This study characterized and reconstructed phylogenetic analysis of 23 ORF2 of PCV2 strains obtained from pigs with PCV2-associated systemic infection and healthy pigs during 2002 -2010. Molecular characterization of the isolates was based on the analysis of cap gene. This region is 
suitable for genotyping studies and is considered a reliable phylogenetic marker for PCV2 strains since it is possible to reconstruct the same tree as with the whole viral genome [11]. Porcine circovirus type 2 (PCV2) is divided into two major genotypes based on sequencing analysis. Recently, both genotypes were proposed and referred to as PCV2a and PCV2b [31].

The alignment of the amino acid sequences of the ORF2 PCV2 capsid protein performed in the present study has identified three major regions of amino acid heterogeneity located at amino acid positions 57 -89, 121 - 134 and 190- 210 within heterogenic regions (Figure 3) similar to previous reports [24,32]. It is interesting to note that two of these regions (57-89 and 121134) correspond with two dominant immunoreactive areas (65-87 and 113-139) as identified by Pepscan analysis [32]. These immunodominant regions of the capsid protein of PCV2 exposed to selective immune pressure could represent potential candidate regions involved in the emergence of PCV2 variants. However, no repeatable or characteristic amino acid motifs for these two regions of the capsid protein of PCV2 could be associated with strains identified from pigs with PCV2-associated systemic infection or healthy pigs. Whether the anti-PCV2 antiserum generated from Colombian PCV2 strains could recognize the same epitopes in strains from other countries is not yet known but the results presented here contribute to the knowledge of the variability of the immunoreactive regions among PCV2 strains.

In terms of PCV2 genotype and its dynamics over time, there was not a relationship between the genotype of PCV2 and year of detection. Among the 23 Colombian PCV2 strains in this study, the strain CO6602 collected in 2002 belonged to the genotype PCV2b, whereas in the period from 2002 to 2010, in spite of being genotype $2 b$ more prevalent, the isolates were a mix of genotypes PCV2a and PCV2b. The results presented here suggest that PCV2b has become the main genotype acting in Colombia over time. Previous studies revealed that both genotypes were associated with PCVAD-affected and non-affected herds [24,33-35]. Nevertheless, PCV2b is currently prevailing in naturally occurring infections worldwide [36], a similar situation could be occurring in Colombian pig populations.

Furthermore, several recent publications have reported a shift from the genotype PCV2a to PCV2b which might be related to the occurrence of PCVAD outbreaks in Canada [37], Sweden [38], Switzerland [35] and Spain [39], indicating that PCV2b may be more virulent than PCV2a. However, in Colombia PCV2b has been present since 2002 in healthy animals and then it was associated to the PCVAD epizootic occurrence in farms of several regions of the country in the period $2006-2009$. Nevertheless, in farm 2 a shift from PCV2a (2005) to PCV2b
(2006) was found and, in farm 18 the variation was from PCV2b (2006) to PCV2a (2009). In addition, the PCV2b strains CO6602 and CO2906 collected in the same farm in the years 2002 and 2006 respectively showed less than $1.3 \%$ differences in the amino acid sequence of ORF2. It is well known that Colombia keeps a wide commercial exchange with North American countries, which includes the import of live animals and semen, so it is not surprising that the strains analyzed in this work were found to be closely related to Canadian and American strains isolated between 2004 - 2010, sharing 74,7\% - 100\% identity at the amino acid level. This coincides with findings in some countries, where the presence of PCV2 has been linked to imported pigs [40] and the movement of asymptomatic PCV2- infected pigs that occurs as a result of the swine trading which has been suggested to be responsible for the rapid spread of PCV2 around the globe. Unfortunately, there is a lack of information regarding the origin of breeding animals in the herds which limits the capacity to shed light over the potential source of infection and why it is not possible to determine the exact year of introduction of PCV2 in Colombian swine farms.

\section{Conclusions}

In Colombia, through the results presented here, it has been demonstrated that PCV-2 is associated with PCVAD. In this study, 23 ORF2 strains of PCV-2 were obtained from animals with confirmed diagnosis of systemic and subclinical infection originated from different farms in a time frame from 2002 to 2010. Although in South America data regarding molecular characterization of PCV2 strains is still scarce, based on genotyping studies it has been concluded that PCV2b is the predominant circulating genotype in the region. However in Colombia there was a mixture of both genotypes during the epizootic, but recently PCV2b became more common in cases of PCVAD. This finding contributes to the understanding of the molecular epidemiology of PCV2 in Latin-American countries and may also help to establish the bases necessary to study the emergence of new viral variants in this region.

\section{Methods}

\section{Samples}

This study analyzed three different groups of samples, each one from a different time frame. The first group corresponded to a retrospective study that included a total of 110 blood serum samples belonging to the bank sera of the Instituto Colombiano Agropecuario (ICA) collected during 2002 - 2005 as part of the national swine serologic monitoring program which focused on farms with 50 or more sows. Serum samples were from nursery/grower pigs (6-12 weeks of age) from 22 previously reported seropositive farms and they were mostly from animals with unknown or healthy clinical status [22]. The second group of 
Table 4 Accession numbers and geographic origin of the ORF2 sequences included in the phylogenetic analysis

\begin{tabular}{|c|c|c|c|c|}
\hline GenBank accession & PCV2 strain ID/original & Country origin & Genotype & Genotype references \\
\hline AB072302 & No. 26 & Japan & PCV-2a & Imai et al. (2001) \\
\hline AF055391 & nd & USA & PCV-2a & Meehan et al. (1998) \\
\hline AF055392 & nd & Canada & PCV-2a & Meehan et al. (1998) \\
\hline AF109399 & $2-E$ & Canada & PCV-2a & Hamel et al. (2000) \\
\hline AF154679 & nd & Taiwan & PCV2-2a / 2B & Kuo et al. (1999) \\
\hline AF117753 & $2-D$ & Canada & PCV-2a & Hamel et al. (2000) \\
\hline AF201307 & GER3 & Germany & PCV-2a / 2 C & Mankertz et al. (2000) \\
\hline AF201309 & SPA2 & Spain & PCV-2a & Mankertz et al. (2000) \\
\hline AF364094 & nd & Taiwan & PCV-2a & Wang et al. (2001) \\
\hline AF381175 & $\mathrm{BF}$ & China & PCV-2a & Lu et al. (2001) \\
\hline AY180397 & Pingtung-5 & China & PCV-2a & Liao et al. (2002) \\
\hline AY256459 & 336 & Hungary & PCV2-2a $2 C$ & Dan et al. (2003) \\
\hline AY321982 & Fh14 & France & $P C V-2 b$ & de Boisseson et al. (2004) \\
\hline AY321983 & Fh20 & France & $P C V-2 b$ & de Boisseson et al. (2004) \\
\hline AY321984 & $\mathrm{Fd} 3$ & France & $P C V-2 b$ & de Boisseson et al. (2004) \\
\hline AY322001 & Fh21 & France & $P C V-2 b$ & de Boisseson et al. (2004) \\
\hline AY484407 & NL_Control_1 & Netherlands & $P C V-2 b$ & Grierson et al. (2004) \\
\hline AY484412 & NL_Control_6 & United Kingdom & $P C V-2 b$ & Grierson et al. (2004) \\
\hline AY484415 & NL_PMWS_3 & United Kingdom & $P C V-2 b$ & Grierson et al. (2004) \\
\hline AY556477 & HuNan & China & PCV2- 2b $1 C$ & Zhixin et al. (2004) \\
\hline AY678532 & ZS0401 & China & $P C V-2 b$ & Zhou et al. (2004) \\
\hline AY682997 & ZC & China & $P C V-2 b$ & Wang et al. (2004) \\
\hline AY691169 & QZ0401 & China & $P C V-2 b$ & Zhou et al. (2004) \\
\hline AY699793 & nd & USA & PCV2-2a $2 E$ & Fenaux et al. (2004) \\
\hline AY847748 & BJW & Singapore & PCV2-2b 1B & Liu et al. (2005) \\
\hline AY754017 & Aust 6 & Australia & PCV2-2a 2A & Muhling et al. (2005) \\
\hline DQ151643 & GS & China & $P C V-2 b$ & Ma et al. (2005) \\
\hline DQ220728 & FMV05-6317 & Canada & $P C V-2 b$ & Tremblay et al. (2005) \\
\hline DQ220734 & FMV05-7389 & Canada & $P C V-2 b$ & Tremblay et al. (2005) \\
\hline DQ220736 & FMV05-7537 & Canada & $P C V-2 b$ & Tremblay et al. (2005) \\
\hline DQ220739 & FMV05-6302 & Canada & $P C V-2 b$ & Tremblay et al. (2005) \\
\hline DQ233257 & $\mathrm{ROM}$ & Romania & $P C V-2 b$ & Cadar et al. (2007) \\
\hline DQ629115 & n32eu & USA & $P C V-2 b$ & Cheung et al. (2007) \\
\hline DQ629117 & k52 & USA & $P C V-2 b$ & Cheung et al. (2007) \\
\hline DQ861896 & $\operatorname{am} 22$ & Brazil & $P C V-2 b$ & Castro et al. (2006) \\
\hline DQ861899 & am9 & Brazil & $P C V-2 b$ & Castro et al. (2006) \\
\hline DQ861902 & $\operatorname{am} 21$ & Brazil & PCV-2b $1 A$ & Castro et al. (2006) \\
\hline DQ870484 & hk102 & USA & PCV-2a & Cheung et al. (2007) \\
\hline DQ923524 & $15 / 23 R$ & Brazil & $P C V-2 b$ & Dezen et al. (2010) \\
\hline EF524517 & GSO4 & China & PCV-2d & Wang et al. (2009) \\
\hline EF524526 & LN05 & China & PCV-2e & Wang et al. (2009) \\
\hline EF524533 & GX0602 & China & PCV-2e & Wang et al. (2009) \\
\hline EF524539 & TJ06 & China & PCV-2d & Wang et al. (2009) \\
\hline EU057185 & P0404c/03 & Brazil & $P C V-2 b$ & Esteves et al. (2007) \\
\hline
\end{tabular}


Table 4 Accession numbers and geographic origin of the ORF2 sequences included in the phylogenetic analysis (Continued)

\begin{tabular}{|c|c|c|c|c|}
\hline EU148503 & DK1980PMWSfree & Denmark & PCV-2C & Dupont et al. (2008) \\
\hline EU148505 & DK1990PMWSfree & Denmark & PCV-2C & Dupont et al. (2008) \\
\hline EU186062 & Chile C & Chile & $P C V-2 b$ & Bucarey et al. (2007) \\
\hline EF394775 & $05-22779$ & Canada & PCV2 -2a 2E & Tremblay et al. (2007) \\
\hline EU519223 & Chile-l & Chile & $P C V-2 b$ & Bucarey et al. (2007) \\
\hline EU747125 & PCU1 & Korea & PCV-2a & Vijayachandran et al. (2008) \\
\hline EU755378 & BRA9 & Brazil & $P C V-2 b$ & Chiarelli-Neto et al. (2009) \\
\hline EU980087 & isolate 5 & Argentina & $P C V-2 b$ & Pereda et al. (2008) \\
\hline EU980092 & isolate 11 & Argentina & $P C V-2 b$ & Pereda et al. (2008) \\
\hline EU980093 & isolate 11 & Argentina & $P C V-2 b$ & Pereda et al. (2008) \\
\hline FJ233907 & SoPCV2b & Canada & $P C V-2 b$ & Chaiyakul et al. (2008) \\
\hline FJ475129 & BJ-1 & China & PCV1 & Zhou et al. (2008) \\
\hline FJ905463 & C7155 & Korea & $P C V-2 b$ & Kim et al. (2009) \\
\hline FJ905471 & C7189 & Korea & PCV-2a & Kim et al. (2009) \\
\hline FN398024 & Villa Clara V2 & Cuba & $P C V-2 b$ & Pérez et al. (2010) \\
\hline FN398025 & Villa Clara V4 & Cuba & $P C V-2 b$ & Pérez et al. (2010) \\
\hline FN398026 & Pinar del Rio & Cuba & $P C V-2 b$ & Pérez et al. (2010) \\
\hline GQ404852 & MN614 & USA & $P C V-2 b$ & Li et al. (2010) \\
\hline GU049341 & Sp-10-7-54-13 & Spain & $P C V-2 b$ & Fort et al. (2010) \\
\hline GU049342 & Sp-10-7-54-13 & Spain & $P C V-2 b$ & Fort et al. (2010) \\
\hline JN644769 & SeUy1 & Uruguay & $P C V-2 b$ & Ramos et al. (2010) \\
\hline JN644770 & SeUy2 & Uruguay & $P C V-2 b$ & Ramos et al. (2010) \\
\hline JN644771 & SeUy3 & Uruguay & $P C V-2 b$ & Ramos et al. (2010) \\
\hline
\end{tabular}

samples was from archived necropsy material collected between July 2006 and May 2007 from pigs with historical records of PCV2-associated systemic infection (by immunohistochemistry assays) from eleven different herds of four Colombian geographic regions (Table 1).

Additionally, a third group of serum and tissue samples collected between January 2009 and February 2010 were also examined (Table 2). Five pigs per farm from the 27 farms evaluated were used for serum collection. The criteria for serum selection included the age (between 8 and 15 weeks), weight (under $60 \mathrm{~kg}$ ) and no clinical evidence of PCVAD in the animals. A total of 50 pigs, between 6 to 16 weeks old, with wasting problems after weaning were investigated in 18 of these farms. Field veterinarians selected $1-5$ pigs from each farm based on loss of body condition, with the additional clinical signs of diarrhea, skin pallor, and/or respiratory disorders. Clinical samples (popliteal and inguinal lymph nodes, tonsil, spleen and kidney) of the affected euthanized animals were collected. The samples were kept at $-70^{\circ} \mathrm{C}$ until performing DNA extraction and PCR analysis.

\section{DNA extraction and PCV2 DNA amplification}

The DNA was extracted from $200 \mu \mathrm{l}$ of serum or $20 \mathrm{mg}$ of organ tissue homogenate using a commercial kit (QIAamp DNA Mini Kit, Qiagen, USA) according to the manufacturer's recommendations. To avoid cross contamination, samples were processed individually and stored at $-20^{\circ} \mathrm{C}$.

Conventional PCR for PCV-2 was performed using primers previously described [41] which amplified a 657 base pair (bp) fragment. The forward primer (5'-GCC AGTTCGTCACCCTTTC-3') was located between genomic positions 940 and 958 (found in PCV2 ORF1). The reverse primer (5'-CTCCCGCACCTTCGGATAT-3') was located between positions 1578 and 1596 (found in PCV2 ORF2). The optimized PCR reaction mixture contained $200 \mathrm{nM}$ dNTPs, $1.5 \mathrm{mM} \mathrm{MgCl}, 1 \times$ PCR buffer, $500 \mathrm{nM}$ of each primer and $0.05 \mathrm{U}$ of Taq polymerase (Promega M8298) in a $25 \mu \mathrm{l}$ final volume.

The reactions were run in a thermocycler Bio Rad ALS-1296 (Bio-rad Laboratories, Inc USA) under the following conditions: one cycle at $94^{\circ} \mathrm{C}$ for $5 \mathrm{~min}$, followed by 35 cycles of $94^{\circ} \mathrm{C}$ during $30 \mathrm{~s}$, primer annealing $64^{\circ} \mathrm{C}$ for $1 \mathrm{~min}$, initial extension at $72^{\circ} \mathrm{C}$ for $30 \mathrm{~s}$, 
and a final extension of $72^{\circ} \mathrm{C}$ for $7 \mathrm{~min}$. The amplified product was visualized by standard gel electrophoresis of $10 \mu \mathrm{l}$ of the final reaction mixture on a $1.5 \%$ agarose gel (Sigma A-9539) in TBE Buffer 10× (Invitrogen 15581044). Amplified DNA fragments of specific size were observed by ultraviolet fluorescence after staining with EZ Vision $^{\text {Tx }}$ Three (Amresco N-313, USA). The length was verified by a 100 bp DNA ladder (Invitrogen 15628-019). Control DNA from a PCV2 strain (Genbank accession number JF290418) was included in each reaction.

\section{PCR amplification of ORF2 gene}

One set of specific PCV2 primers, based on PCV2 genome from the strain ZhuJi2003 (AY579893) published in the Gen Bank was designed to amplify the complete ORF2 PCV2 sequence. A full-length ORF2 gene of PCV2 was amplified by PCR with forward primer (capFw 5'CCGTTGGAATGGTACTCCTC 3') located between genomic positions 825 and 844 (found in PCV2 ORF1). The reverse primer (cap Rw 5' ACAGCGC ACTTCTTTCGTTT3') was located between positions 1760 - 1741 (found in PCV2 ORF2). PCV2 specific primers amplified a 935 bp DNA fragment. The optimized PCR reaction mixture contained $200 \mathrm{nM}$ dNTPs, $1.5 \mathrm{mM} \mathrm{MgCl}, 1 \times$ PCR buffer, $600 \mathrm{nM}$ of each primer and $0.05 \mathrm{U}$ Taq polymerase (Promega M8298). Reaction conditions were as follows: initial denaturation at $94^{\circ} \mathrm{C}$ for $5 \mathrm{~min}$, followed by 35 cycles of $95^{\circ} \mathrm{C}$ during $45 \mathrm{~s}$, primer annealing $57^{\circ} \mathrm{C}$ for $45 \mathrm{~s}$, initial extension at $72^{\circ}$ for $45 \mathrm{~s}$, and a final extension of $72^{\circ} \mathrm{C}$ for $12 \mathrm{~min}$.

The specificity of the primers was tested by adding extracted nucleic acids from several viral and bacterial swine pathogens such as: Actinobacillus pleuropneumoniae, (ATCC 27088), Mycoplasma hyopneumoniae (field strain), Haemophilus parasuis (ATCC 19417), Streptococcus suis (ATCC 700794), swine influenza virus H1N1 (A/SW/ Iowa/H1N1 NVSL 003 IDV 9501), porcine reproductive and respiratory syndrome virus (NVSL 130 PDV 9801), Aujeszky's disease virus (Shope strain NVSL 070 PDV), porcine parvovirus (Mengeling strain NVSL 080PDV9501) and porcine circovirus type 1. Control DNA from PCV1 was obtained from the supernatant of the PK15 cell line, which is persistently infected with this virus (ATCC CCL-33). The sensitivity of the PCV2 PCR was estimated through the evaluation of serial DNA dilutions extracted from the PCV2 positive control. The amplified products were run in a $1.5 \%$ agarose gel and visualized by staining with EZ VisionTM (Amresco $\mathrm{N}-313$, USA).

\section{Viral sequences and phylogenetic analysis}

DNA fragments of the calculated sizes were excised and recovered from the agarose gel using spin columns as described by the manufacturer (QIAquick Gel Extraction
Kit, Qiagen 2876, USA). The purified PCR products were used as templates in cycle sequencing reactions primed with the PCV2 primers (capFw, capRw) and sequenced in both directions by Macrogen Sequencing Service, USA. Sequence alignment was performed using ClustalW software; genotype studies were performed by analyzing ORF2 compared to published sequences corresponding to different genotypes. The degree of identity among sequences at the nucleotide and amino acid levels was determined using BioEdit package v.7.0.9 [42]. The phylogenetic tree was constructed by neighborjoining method with the Kimura two-parameter as the model of nucleotide substitution using MEGA v.5.0 software [43]. Confidence in the NJ tree was estimated by 1000 bootstrap replicates.

The sequencing of ORF2 presented greater difficulties with the electropherograms, with lower quality peaks. Only 23 were considered of good quality, with a definitive interpretation of the base sequence. The phylogenetic tree was constructed for ORF2 by comparing positive samples from various regions of Colombia as well as 68 sequences from the GenBank database, representative of all PCV2 genotypes described in North America, South America, Europe, Cuba and Asian countries (Table 4). The tree was rooted with a PCV1 sequence (accession number FJ475129).

\section{Abbreviations \\ PCVAD: Porcine circovirus-associate disease; PCV2: Porcine circovirus type 2; DNA: Deoxyribonucleic acid; PCVD: Porcine circovirus diseases; ORF: Open reading frame; TCID50: 50\% Tissue Culture Infective Dose; I: Isoleucine; V: Valine; K: Lysine; A: Alanine; T: Threonine; L: Leucine; F: Phenylalanine; D: Aspartic acid; K: Lysine; N: Asparagine; Q: Glutamine; PCR: Polymerase chain reaction; dNTPs: Deoxynucleotide triphosphates; MgCl: Magnesium chloride; ATCC: American Type Culture Collection; NVSL: National Veterinary Services Laboratories.}

\section{Competing interests}

The authors declare that they have no competing interest.

\section{Authors' contributions}

MARM, JDMG, GCRN, VJV, JJC designed the study. MARM prepared virus isolates and clinical data. MARM conducted experiments. MARM, JDMG, GCRN contributed to analysis and interpretation of data. MARM, JDMG, GCRN, VJV and JJC wrote the manuscript. All authors read and approved the final manuscript.

\section{Acknowledgements}

The authors extend their gratitude to Dr. Michael P Murtaugh from the Department of Veterinary Population Medicine, University of Minnesota for providing the positive controls for PCV-2. This work was supported by the Ministry of Agriculture and Rural Development (Project number 202010010941) and the Colombian Swine Producers Association. The funding sources did have no influence on the writing of the manuscript and the decision to submit the manuscript for publication.

Received: 20 January 2014 Accepted: 9 July 2014

Published: 8 August 2014

\section{References}

1. Allan GM, Ellis JA: Porcine circoviruses: a review. J Vet Diagn Invest 2000, $12: 3-14$. 
2. Opriessnig T, Meng XJ, Halbur PG: Porcine circovirus type 2 associated disease: update on current terminology, clinical manifestations, pathogenesis, diagnosis, and intervention strategies. J Vet Diagn Invest 2007, 19:591-615.

3. Chae C: Postweaning multisystemic wasting syndrome: a review of aetiology, diagnosis and pathology. Vet J 2004, 168:41-49.

4. Harding JC: The clinical expression and emergence of porcine circovirus 2. Vet Microbiol 2004, 98:131-135.

5. Rosell C, Segales J, Plana-Duran J, Balasch M, Rodriguez-Arrioja GM, Kennedy S, Allan GM, McNeilly F, Latimer KS, Domingo M: Pathological, immunohistochemical, and in-situ hybridization studies of natural cases of postweaning multisystemic wasting syndrome (PMWS) in pigs. J Comp Pathol 1999, 120:59-78.

6. Hamel AL, Lin LL, Nayar GP: Nucleotide sequence of porcine circovirus associated with postweaning multisystemic wasting syndrome in pigs. J Virol 1998, 72:5262-5267.

7. Niagro FD, Forsthoefel AN, Lawther RP, Kamalanathan L, Ritchie BW, Latimer KS, Lukert PD: Beak and feather disease virus and porcine circovirus genomes: intermediates between the geminiviruses and plant circoviruses. Arch Virol 1998, 143:1723-1744.

8. Mankertz A, Hillenbrand B: Replication of porcine circovirus type 1 requires two proteins encoded by the viral rep gene. Virology 2001, 279:429-438.

9. Mankertz A, Mueller B, Steinfeldt T, Schmitt C, Finsterbusch T: New reporter gene-based replication assay reveals exchangeability of replication factors of porcine circovirus types 1 and 2. J Virol 2003, 77:9885-9893.

10. Nawagitgul P, Morozov I, Bolin SR, Harms PA, Sorden SD, Paul PS: Open reading frame 2 of porcine circovirus type 2 encodes a major capsid protein. J Gen Virol 2000, 81:2281-2287.

11. Olvera A, Cortey M, Segales J: Molecular evolution of porcine circovirus type 2 genomes: phylogeny and clonality. Virology 2007, 357:175-185

12. Liu J, Chen I, Kwang J: Characterization of a previously unidentified viral protein in porcine circovirus type 2 -infected cells and its role in virus-induced apoptosis. J Virol 2005, 79:8262-8274.

13. Karuppannan AK, Kwang J: ORF3 of porcine circovirus 2 enhances the in vitro and in vivo spread of the of the virus. Virology 2011, 410:248-256.

14. Dupont K, Nielsen EO, Baekbo P, Larsen LE: Genomic analysis of PCV2 isolates from Danish archives and a current PMWS case-control study supports a shift in genotypes with time. Vet Microbiol 2008, 128:56-64.

15. Gagnon CA, Music N, Fontaine G, Tremblay D, Harel J: Emergence of a new type of porcine circovirus in swine (PCV): a type 1 and type 2 PCV recombinant. Vet Microbiol 2010, 144:18-23.

16. Wang F, Guo X, Ge X, Wang Z, Chen Y, Cha Z, Yang H: Genetic variation analysis of Chinese strains of porcine circovirus type 2. Virus Res 2009, 145:151-156.

17. Cortey M, Olvera A, Grau Roma L, Segales J: Further comments on porcine circovirus type 2 (PCV2) genotype definition and nomenclature. Microbiol 2011, 149:522-523

18. Ciacci-Zanella JR, Simon NL, Pinto LS, Viancelli A, Fernandes LT, Hayashi M, Dellagostin OA, Esteves PA: Detection of porcine Circovirus type 2 (PCV2) variants PCV2-1 and PCV2-2 in Brazilian pig population. Res Vet Sci 2009, 87:157-160

19. Pereda A, Pineyro P, Bratanich A, Quiroga MA, Bucafusco D, Craig MI, Cappuccio J, Machuca M, Rimondi A, Dibarbora M, Sanguinetti HR, Perfumo CJ: Genetic characterization of porcine circovirus type 2 from pigs with porcine circovirus associated diseases in Argentina. Vet Sci 2011, 2011:560905.

20. Sarradell J, Perez AM, Andrada M, Rodriguez F, Fernandez A, Segales J: PMWS in Argentina. Vet Rec 2002, 150:323.

21. Ruiz A, Gutierrez C, Ramirez E, Quezada M, Lecocq C, Segales J: Postweaning multisystemic wasting syndrome in Chile. Vet Rec 2007, 161:496

22. Clavijo Hoyos JA, Mogollón Galvis JD, Rincon MA: Circovirus porcino tipo 2 (PCV2) en Colombia evaluación serológica, caracterización histopatológica de las lesiones y detección del antigéno viral mediante inmunohistoquímica. Universidad Nacional de Colombia: Facultad de Medicina Veterinaria y Zootecnia; 2007.

23. Díaz Jiménez CA: Caracterización epidemiológica del Síndrome de Emaciación Postdestete (PMWS) en granjas tecnificadas de Colombia, Universidad Nacional de Colombia (Bogotá), Facultad de Medicina Veterinaria y de Zootecnia Posgrado en Salud y Producción Animal. 2010.

24. Grau-Roma L, Crisci E, Sibila M, Lopez-Soria S, Nofrarias M, Cortey M, Fraile L, Olvera A, Segales J: A proposal on porcine circovirus type 2 (PCV2) genotype definition and their relation with postweaning multisystemic wasting syndrome (PMWS) occurrence. Vet Microbiol 2008, 128:23-35.
25. Jacobsen B, Krueger L, Seeliger F, Bruegmann M, Segales J, Baumgaertner W: Retrospective study on the occurrence of porcine circovirus 2 infection and associated entities in Northern Germany. Vet Microbiol 2009, 138:27-33.

26. Grierson SS, King DP, Sandvik T, Hicks D, Spencer Y, Drew TW, Banks M: Detection and genetic typing of type 2 porcine circoviruses in archived pig tissues from the UK. Arch Virol 2004, 149:1171-1183.

27. Staebler S, Sydler T, Buergi E, McCullough K, McNeilly F, Allan G, Pospischil A: PMWS: an emerging disease identified in archived porcine tissues. Vet J 2005, 170:132-134.

28. Rodriguez-Arrioja GM, Segales J, Rosell C, Rovira A, Pujols J, Plana-Duran J, Domingo M: Retrospective study on porcine circovirus type 2 infection in pigs from 1985 to 1997 in Spain. J Vet Med B Infect Dis Vet Public Health 2003, 50:99-101.

29. Mori M, Sato K, Akachi S, Asahi S, Taniguchi S, Narita M: Retrospective study of porcine circovirus 2 infection in Japan: seven cases in 1989. Vet Pathol 2000, 37:667-669.

30. Kiatipattanasakul Banlunara W, Tantilertcharoen R, Suzuki K, Albarenque SM, Thanawongnuwech $\mathrm{R}$, Nakayama $\mathrm{H}$, Doi K: Detection of porcine circovirus 2 (PCV-2) DNA by nested PCR from formalin-fixed tissues of post-weaning multisystemic wasting syndrome (PMWS) pigs in Thailand. J Vet Med Sci 2002, 64:449-452.

31. Segales J, Olvera A, Grau-Roma L, Charreyre C, Nauwynck H, Larsen L, Dupont K, McCullough K, Ellis J, Krakowka S, Mankertz A, Fredholm M, Fossum C, Timmusk S, Stockhofe-Zurwieden N, Beattlle V, Armstrong D, Grassland B, Baekbo P, Allan G: PCV-2 genotype definition and nomenclature. Vet Rec 2008, 162:867-868

32. Mahe D, Blanchard P, Truong C, Arnauld C, Le Cann P, Cariolet R, Madec F, Albina $E$, Jestin A: Differential recognition of ORF2 protein from type 1 and type 2 porcine circoviruses and identification of immunorelevant epitopes. J Gen Virol 2000, 81:1815-1824.

33. Cheung AK, Lager KM, Kohutyuk OI, Vincent AL, Henry SC, Baker RB, Rowland RR, Dunham AG: Detection of two porcine circovirus type 2 genotypic groups in United States swine herds. Arch Virol 2007, 152:1035-1044.

34. Carman S, McEwen B, DeLay J, van Dreumel T, Lusis P, Cai H, Fairles J: Porcine circovirus-2 associated disease in swine in Ontario (2004 to 2005). Can Vet J 2006, 47:761-762.

35. Wiederkehr DD, Sydler T, Buergi E, Haessig M, Zimmermann D, Pospischil A, Brugnera $E$, Sidler $X$ : A new emerging genotype subgroup within PCV-2b dominates the PMWS epizooty in Switzerland. Vet Microbiol 2009, 136:27-35.

36. Firth C, Charleston MA, Duffy S, Shapiro B, Holmes EC: Insights into the evolutionary history of an emerging livestock pathogen: porcine circovirus 2. J Virol 2009, 83:12813-12821.

37. Gagnon CA, Tremblay D, Tijssen P, Venne MH, Houde A, Elahi SM: The emergence of porcine circovirus $2 b$ genotype (PCV-2b) in swine in Canada. Can Vet J 2007, 48:811-819.

38. Timmusk $S$, Wallgren $P$, Brunborg IM, Wikstrom FH, Allan G, Meehan B, McMenamy M, McNeilly F, Fuxler L, Belak K, Podersoo D, Saar T, Berg M, Fossum C: Phylogenetic analysis of porcine circovirus type 2 (PCV2) pre- and post-epizootic postweaning multisystemic wasting syndrome (PMWS). Virus Genes 2008, 36:509-520.

39. Cortey M, Pileri E, Sibila M, Pujols J, Balasch M, Plana J, Segales J: Genotypic shift of porcine circovirus type 2 from PCV-2a to PCV-2b in Spain from 1985 to 2008. Vet J 2010, 187:363-368.

40. Chiarelli-Neto O, Yotoko KS, Vidigal PM, Silva FM, Castro LA, Fietto JL, Silva A Jr, Almeida MR: Classification and putative origins of Brazilian porcine circovirus 2 inferred through phylogenetic and phylogeographical approaches. Virus Res 2009, 140:57-63.

41. Quintana J, Balasch M, Segales J, Calsamiglia M, Rodriguez-Arrioja GM, Plana-Duran J, Domingo M: Experimental inoculation of porcine circoviruses type 1 (PCV1) and type 2 (PCV2) in rabbits and mice. Vet Res 2002, 33:229-237.

42. TA H: Bioedit: a user-friendly biological sequence alignment editor and analysis program for windows 95/98/NT. Nucl Acids Symp 1999, 41:95-98.

43. Tamura K, Dudley J, Nei M, Kumar S: MEGA4: Molecular Evolutionary Genetics Analysis (MEGA) software version 4.0. Mol Biol Evol 2007, 24:1596-1599.

doi:10.1186/1743-422X-11-143

Cite this article as: Rincón Monroy et al:: Detection and molecular characterization of porcine circovirus type 2 from piglets with Porcine Circovirus Associated Diseases in Colombia. Virology Journal 2014 11:143. 